\title{
"Can I have a grade bump?" The Contextual Variables and Ethical Ideologies that Inform Everyday Dilemmas in Teaching
}

\author{
Kristie R. Dukewich, Kwantlen Polytechnic University \\ Suzanne Wood, University of Toronto
}

Educators are regularly confronted with moral dilemmas for which there are no easy solutions. Increasing course sizes and program enrolments, coupled with a new consumerist attitude towards education, have only further exacerbated the quantity and quality of students' requests for special academic consideration (Macfarlane, 2004). Extensions, late submissions, and grade bumps-once rare - are now commonplace. However, there is very little in the pedagogical literature that addresses these everyday dilemmas. In a culture of transparency, unspoken policies that address these requests are the form of learner consideration that is the least transparent to students and educators alike. Here we explore some of the variables that contribute to the complexity of these dilemmas, and the ethical ideologies that can inform their resolution. Our goal is not to provide best practices, but rather to facilitate reflection about how individuals make these decisions. The idiosyncratic nature of these decisions can be framed as a reflection of different ethical ideologies, and we describe one approach to framing individual ethical ideologies from the business literature. Finally, we consider whether faculty should be making these decisions at all, using the centralization of academic integrity (cf. Neufeld \& Dianda, 2007) as a model, and explore its parallels with issues around ethical dilemmas in teaching.

\section{Introduction}

When I started teaching as a graduate student, I
was amazed at the number of students requesting exceptions to the course policies. Since then, both the number of requests for special treatment and the kinds of requests that I receive from students have only increased. Students regularly ask me for extensions on assignments because they are busy. Students ask me to accept homework after the deadline has passed because they forgot to submit. Students contest the application of late penalties described in the syllabus because once it is applied to them, the penalties seem unfair. Students ask me to be excused from in-class assignments because they have tickets to a concert. I have always been most incredulous about students who ask me to increase their final grade for reasons that are unrelated to the quality of their work.

Despite my early career amazement, I am regularly conflicted about how to respond to these requests. Some requests are clearly unreasonable, and those requests are easy to answer. However, some requests really are ethical dilemmas because they pit two or more of my ethical values against each other (Shapira-Lishchinsky, 2011). Often I have to weigh an individual's well-being against the well-being of 
the community or class. Or I have to weigh justice against mercy. These situations are dilemmas because they come down to a right versus a right. Which course of action is more right?

Macfarlane (2004) describes a number of factors that have led to an increase in students' requests for special academic consideration. The first is a shift in power, from absolute power in the hands of the faculty, to a wider distribution of power shared between administrators, faculty, and students. The shift has not been entirely unwarranted. In the past, academia was an elite pursuit, and faculty could make arbitrary decisions with impunity, creating a very real possibility for the abuse of power (Macfarlane, 2004). However, recent trends in higher education have made this status quo untenable. More students have access to higher education, and our student body is more diverse than ever in terms of previous education, ethnic backgrounds, and socioeconomic status (Fenwick, 2005). Worldwide, there has been an increase in course sizes and program enrolments (Altbach, Reisberg \& Rumbley, 2009). Students now have more choice than ever regarding the school they attend or the program they select. Some administrators have embraced the student-asconsumer model, suggesting that it is precisely this marketization of higher education that is responsible for increasing the diversity and quality of the student experience (Scott, 1999). But we are also at a point where we have a better understanding of the diversity of students' needs, from the impact of gender and minority status on the student experience (Brown, 2004), to students' individual differences in learning styles, approaches to studying, and intellectual development (Felder \& Brent, 2005).

My struggle with these dilemmas revolves around three facts. First, there is not much of a conversation around how these decisions are made. Despite seriously investing in my professional development around teaching, I found that the workshops and conferences I attended did not speak to these dilemmas. Second, there is only a sparse literature around these sorts of ethical dilemmas (Barnett, 2004). If an instructor takes an evidencebased approach to teaching, pedagogical research does not provide much guidance on this topic. And third, talking to colleagues about my dilemmas only further exacerbated my anxiety about how to respond. I found many of my colleagues assumed that there was an obvious answer to these dilemmas, but where one colleague might advise, "Obviously you should grant the request," another colleague might advise, "Obviously you shouldn't grant the request." I was confused: why wasn't anyone telling me how to deal with these dilemmas? Why didn't the university give me rules or guidelines for these decisions?

To try to answer some of these questions, my colleague, Dr. Suzanne Wood, and I decided to engage in pedagogical inquiry on this topic. The results of our inquiry were developed into a session for the 2015 Society for Teaching and Learning in Higher Education in Vancouver, British Columbia.

\section{Is it Possible to Develop a Set of Best Practices for Responding to these Everyday Ethical Dilemmas?}

In our session at the 2015 Society for Teaching and Learning in Higher Education, we asked participants to consider several vignettes that described everyday ethical dilemmas in teaching along with different possible courses of action (see Appendix A for a full reproduction of these vignettes and choices). This approach was motivated by Bruce Macfarlane's (2002, 2004) work. Macfarlane has been breaking new ground on thoughtful discussions around professional ethics in higher education, considering perspectives that have largely been ignored. Inspired by Macfarlane's (2002) description of outcomes from a focus group of lecturers considering a fictional case study of multiple teaching dilemmas, we asked our participants to anonymously vote on these vignettes using iClickers, choosing a course of action for each before engaging in discussion with their peers about the variables they considered in making their selection. We discuss the voting results later in this paper. 


\section{Contextual Variables}

Once we finished polling on the vignettes, we asked participants in our session to consider what factors external to their own values they used to inform their decisions. Many of those identified were also variables we recognized as possibly influencing these decisions, listed in Table 1.

We further identified several variables that were not discussed by participants, but which might play a role in these kinds of decisions for other instructors, including the size of the university and the size of the class. In particular, these factors impact how well we are able to know our students. Rigid rules and a one-size-fits-all approach to course policies are more likely when class enrolments are so large that instructors are only able to be familiar with a handful of students (Macfarlane, 2004).
We also identified two contextual variables that may play a role in these decisions, but which instructors may be reluctant to admit-racial and gender biases, and seniority. Research has shown that people are subject to implicit biases (Greenwald, McGhee \& Schwartz, 1998), showing evidence of the implicit expression of prejudices that they would not verbally admit to possessing. While it is uncomfortable to think so, the gender and race of the student who is is requesting the exception may influence instructors more than they care to admit. While most of the research on implicit biases uses undergraduates as participants, demonstrating possible biases in their interaction with faculty, recent research demonstrates that faculty are not immune to bias. Milkman, Akinola and Chugh (2015) investigated the influence of gender and race on the likelihood that a faculty member would reply to a

\section{Table 1}

Contextual variables and their possible values

\begin{tabular}{lll}
\hline Variable & & Possible Value $^{1}$ \\
\hline Explicit & & \\
& Weight of the assignment & Low-stakes vs. high-stakes \\
& Level of consideration & Small exception vs. big exception \\
& Reason for asking & Emergency vs. non-emergency \\
& Student's personal circumstances & Experiencing difficulty vs. no difficulties \\
& Documentation & Has vs. doesn't have \\
& Prior interactions with the student & Habitual requests vs. first request \\
& Student's standing & Strong vs. weak \\
& Amount of work it generates & Some vs. none \\
Size of the university or class & Small vs. large \\
& & \\
Race and gender of the student & Male vs. female, Caucasian vs. minority \\
& Instructor's seniority & Pre-promotion vs. post-promotion
\end{tabular}

\footnotetext{
${ }^{1}$ All of these possible values have been treated as discrete, however many of them are actually continuous variables that include a great number of possible values for the variable (ex. weight of the assignment).
} 
(fictional) student interested in pursuing graduate studies with him/her. The large sample of faculty members who received the emails were selected from 259 institutes and across a wide variety of disciplines and departments. The researchers found a consistent and substantial advantage in getting a reply for students with names readily identified as belonging to someone Caucasian and male. For most disciplines, students with names readily identified as belonging to minorities or females were far less likely to hear back. The results strongly suggest that many instructors have implicit racial and gender biases that inform their decisions about requests for special treatment. However, ignoring these biases or denying they exist is the best way to guarantee that they continue to negatively impact students (Sleeter, 2015). Acknowledging these biases, while uncomfortable, is the first step in ensuring that instructors are equitable and reflective in their approach to the diversity among their students.

We also discussed the impact of seniority on how these decisions are made. New faculty members are often under incredible pressure to produce favorable student evaluations of teaching (SETs; Eiszler, 2002). While many universities see SETs as a kind of formative feedback to instructors, SETs are still widely used in summative assessments of job performance (Gravestock \& Gregor-Greenleaf, 2008), playing an important role in decisions about merit pay and promotion (Beran, Violato \& Kline, 2007). The power that SETs gives students is part of the evolution of higher education to be more accountable for delivering measurable learning outcomes (Nasser \& Fresko, 2002). However, the unintended consequence is that it feeds into the student-as-consumer model, with the corollary instructor-as-service-provider (Scott, 1999). If teaching evaluations still figure prominently in an instructor's career success, they may be more inclined to acquiesce to students' requests for exceptions to course policies, even to the detriment of the student.

While participants acknowledged the consideration of external contextual variables as contributing to their decision process, we have to ask the question: should they?

\section{Ethical ideologies}

Reasonable people can disagree. Two faculty members faced with the same request from the same student may choose two completely different courses of action. Individual differences in ethical reasoning can be framed using Forsyth's (1980) ethical ideologies framework (see also Macfarlane, 2002). Ethical ideologies describe how an individual organizes his or her values and beliefs around ethical behavior.

Forsyth's (1980) framework is a matrix with two axes: idealism and relativism. Idealism reflects a person's belief about harm to others. People who rate high on idealism tend to endorse the idea that a course of action is always available in which no one is harmed, while people low on idealism are more likely to concede that sometimes the most appropriate course of action will have innocent casualties. Relativism reflects a person's belief about the role of context. People who rate high on relativism believe moral actions depend on the nature of the situation and the people involved, while people who rate low on relativism are more likely to endorse the notion of moral rules as naturally emerging in the world.

According to Forsyth's (1980) model, these axes combine to produce four separate ethical ideologies (see Figure 1). Absolutists are individuals who believe there are universal moral truths and that in applying the same rules to everyone, the best outcome will always be achieved; bending the rules doesn't help anyone. Exceptionists are individuals who believe that while there are universal moral truths, sometimes exceptions are warranted under extraordinary circumstances. Situationists believe that consideration of the context and specific situation will produce the best outcome for everyone involved. Subjectivists are the most idiosyncratic, and represent individuals who reject universal moral rules, and are not particularly hopeful that a positive outcome for everyone involved is possible. For subjectivists, calling a course of action moral is just another way to say it is subjectively acceptable to the decision-maker.

The vignettes we presented to participants at our STLHE conference workshop included four possible courses of action, each of which 
corresponded to a particular ethical ideology (see Appendix A). All of the vignettes were constructed so as to pit two or more ethical values against each other, and to include a variety of contextual variables. Figure 2 illustrates the outcome of anonymous iClicker polling. What immediately became apparent to us was that participants varied considerably in their choices. While we found that no specific ethical ideology was endorsed more than any other, we noted that the least popular response tended to be that which aligned most closely to the subjectivist viewpoint.

This pattern of response has an important implication: context mattered to many of the participants. The very fact that people's decisions changed as a function of the specific situation suggested that most participants were relativistic in their approach to each situation. While participants voted before our discussion of ethical ideologies, after our explanation of Forsyth's framework, we probed participants and they confirmed as much. Most (approximately 70\%) self-identified as situationists. As most participants did not select the situationist course of action in each vignette, perhaps this selfidentification reflects the participants' willingness to switch ideologies in response to the contextual variables.

Given the idiosyncratic nature of ethical ideologies, and the variety of contextual variables that may or may not influence how an instructor responds to such a request, the bigger question might be, should faculty be making these decisions at all? With the participants in our session, we explored some of the pros and cons to centralizing the decisions (see Table 2 for a summary).

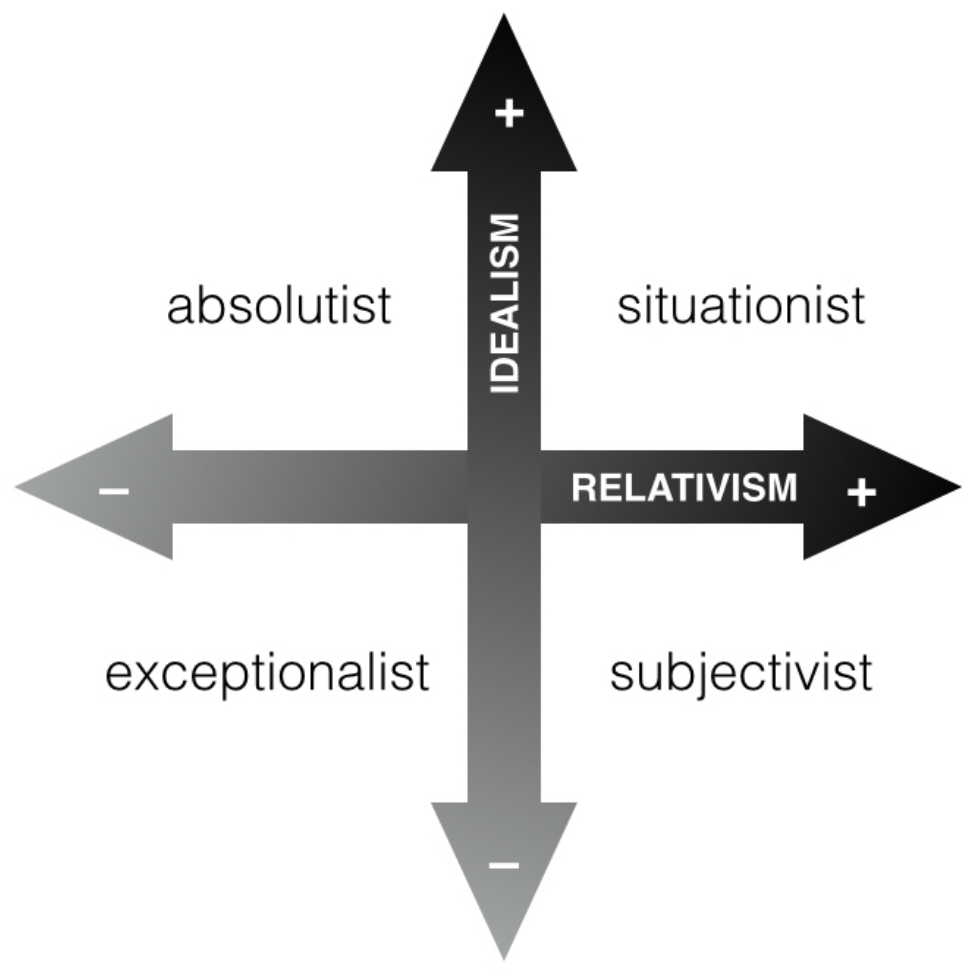

Figure 1

Forsyth's four ethical ideologies plotted as a function of idealism and relativism 


\section{1: Late Homework}

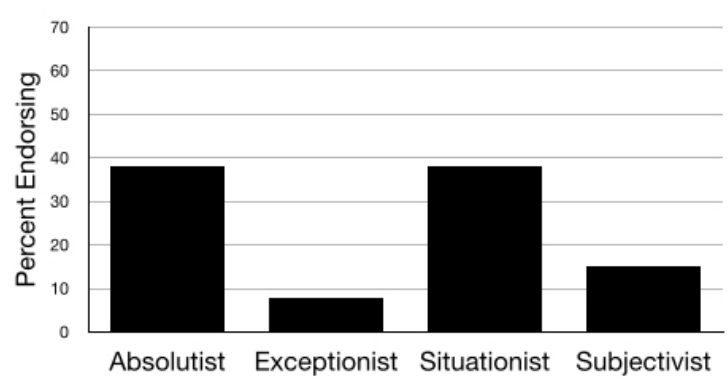

2: Extension

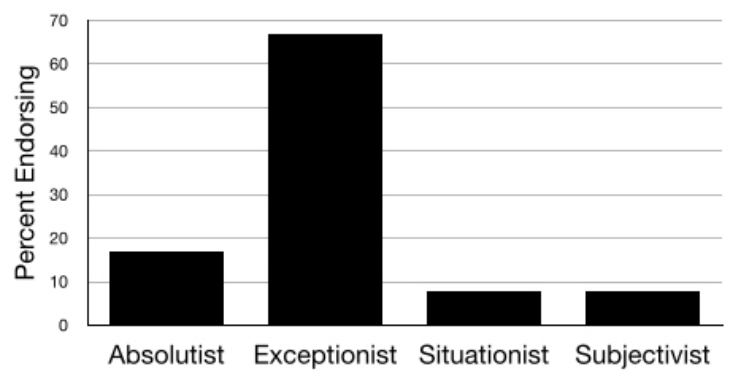

\section{3: Late Penalty}

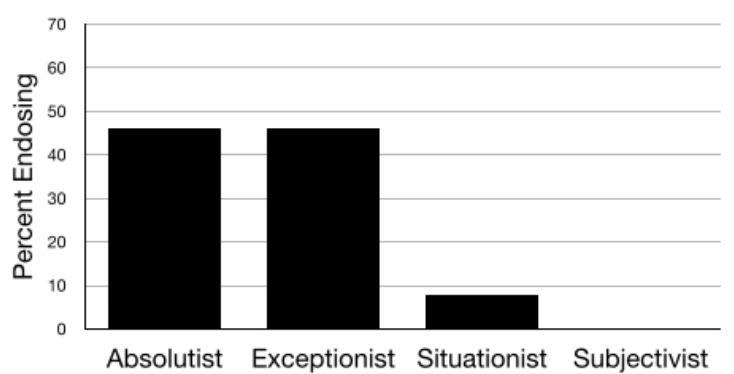

4: Grade Bump

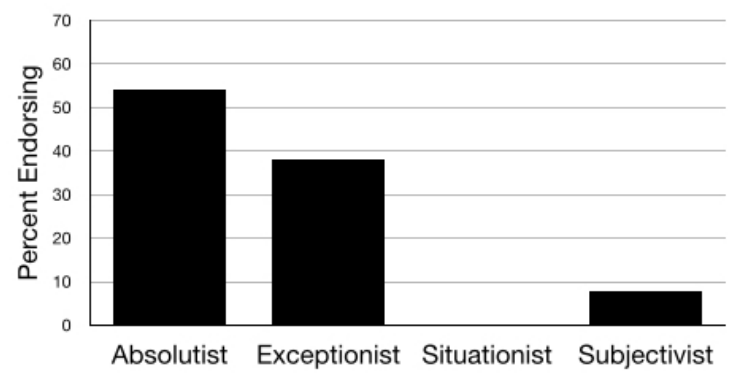

Figure 2

Results from participants' anonymous iClicker polling for each of the vignettes presented (see Appendix A).

Centralizing Decisions: Parallels with the Centralization of Academic Integrity

In order to address this question, we discussed the parallels between how we make decisions regarding special requests and how we handle another form of ethics: academic integrity. In the past, individual faculty members, department chairs, or programs have directly handled academic integrity offenses. Currently, however, academic integrity is typically handled through central offices at institutions throughout North America, with some academics even calling for the standardization of penalties province-wide (Neufeld and Dianda, 2007). The push behind centralization of these types of ethical decisions is rationalized as a way to reduce the burden of time and stress on faculty. Centralization of academic integrity has not been primarily focused on modifying student behaviour, per se. This also parallels the idea behind centralizing special requests, in that the end goal would not necessarily be a reduction in the number of student requests for special consideration, but a reduction in the time necessary to consider these requests by the instructor, and make decision-making for these requests clearer and less arbitrary. Perhaps in examining this history, we could shed some light on whether or not centralizing special requests would be the best plan.

We looked to a nearby university currently pondering the centralization procedure. Western University in London, Ontario, currently trains students about academic integrity through its libraries 


\section{Table 2.}

\section{Pros \& cons identified in the session associated with centralizing decisions for requests for special academic consideration}

\section{PROS}

- Maintain consistency across instructors, courses, departments

- Identify and help students experiencing academic or personal difficulties

- Track students abusing the system

- Adapt to large class sizes often necessary in today's universities

- Lessen concern of impact on teaching evaluations

- Relieve instructor for having sole responsibility for difficult decisions

- Remove concern for additional work by instructor when making decisions and online modules (Meister, 2015). If offenses occur, the instructor, departmental chair, and the dean of the faculty decide upon the penalty. With this system in place, and without an office devoted entirely to academic integrity, the ombudsperson has seen an increase in the number of students using her office for guidance and support through this stressful process (Devlin, 2015). The increase in number of student visits has become a substantial burden that could potentially be alleviated with the formation of an academic integrity office. In addition, the ombudsperson expressed concern regarding inconsistencies among the different campus Faculties in applying penalties (Devlin, 2015). Hypothetically, a student in Engineering could receive a 5\% reduction in grade for an offense which earns a failing grade for a student in Social Sciences.

The above two factors cited by the Western ombudsperson, time burden and inconsistency of enforcement, are compelling reasons to centralize. However, in considering whether this trend has been effective, it is important to remember that the overall goal for any policy is to boost academic integrity, and decrease the number of offenses. If centralizing academic integrity has been successful, we might expect to see decreases in academic integrity violations over the years. Self-report data from 11 Canadian institutions of higher education throughout five provinces indicate that both undergraduate and graduate students continue to engage in dishonest behaviours at high rates (Hughes and McCabe, 2006). Almost one quarter (24\%) of graduate students in the study admit to having copied sentences from a written source without citing it, while $37 \%$ of undergraduates say they have committed this offense. The numbers are similar for undergraduates obtaining test questions from someone who has already completed an exam (38\%). Studies like these point to a serious problem with academic integrity in North America, regardless of recent trends of centralization.

These numbers clearly need to improve. However, if the goal of centralization is about changing the behavior of the faculty rather than the 
students, then the success of centralizing academic integrity might be assessed more effectively by examining faculty outcomes related to academic integrity post-centralization, rather than student outcomes. When faculty members were asked what institutional factors contributed to academic dishonesty, a pattern emerged. Faculty members from 17 universities in 10 Canadian provinces dismissed large class sizes and unqualified students as playing major roles $(9.9 \%$ of respondents selected each of these), while policies being too time-consuming was the factor most selected by participants (30.3\%) (MacLeod, 2014). Faculty say they simply do not have the time to become familiar and follow through with lengthy, bureaucratic procedures. In addition, when asked what course of action they would take if faced with a minor case of academic dishonesty, $42 \%$ of faculty in this study said they would deal with the matter informally. Comments from the faculty point to a variety of reasons for this, one of which is fear that the evidence for the offense would not withstand full legal scrutiny. We wonder if, along these lines, faculty are also concerned that penalties applied at the administrative level could be too harsh for a minor offense. If the university-wide policies are too prescriptive, faculty may be concerned that contextual variables will not be sufficiently weighed (Shapira-Lischinsky, 2011).

On the other hand, administrators throughout U.S. undergraduate and post-secondary institutions were also asked what they thought could be changed to bolster academic integrity (Gallant and Drinan, 2006). Specifically, they were asked what they perceived to be the obstacles to the centralization of academic integrity. In stark contrast to the responses by faculty, administrators uniformly cited the gap between policy and practice being a problem (95.9\%), and specifically a lack of enforcement by faculty $(86.2 \%)$. One of the less selected responses in this group was "cumbersome policies and procedures" (36.6\%). These same administrators were asked who on campus could be the catalyst for change and most effectively strengthen academic integrity (Gallant and
Drinan, 2006). Academic affairs administrators were selected by just $8.0 \%$ of respondents, while faculty was the most popular response (51.3\%).

In sum, administrators see lack of faculty enforcement as a significant obstacle to centralization, but simultaneously look to faculty to enhance academic integrity on campus. If faculty are the key members of the academic community to bring about real change regarding academic integrity, perhaps it follows that they should also be in charge of handling academic integrity within their own classes. One way or another, centralized or not, a significant burden of time falls on the shoulders of faculty. Without centralization, it is up to faculty to report and prosecute violations, and potentially train students. With centralization, administrators believe faculty do not sufficiently enforce the set guidelines, and that it is up to the faculty to create an atmosphere of strong integrity.

Despite the motivations for centralizing academic integrity, centralization has not significantly changed faculty outcomes in the ways originally intended. First of all, the process has not reduced the burden on faculty. In fact, faculty tend to see the new processes as onerous, making many less likely to address potential violations of academic integrity (e.g., MacLeod, 2014). As a result, centralization has not necessarily reduced the arbitrary nature of the consequences for violations of academic integrity. In the current climate, a student who engages in a violation of integrity might be referred to the office of academic integrity by one instructor-leading to expulsion of the student after a long and arduous process - or the violation might be completely ignored by another instructor. While centralized academic integrity does not precisely mirror the potential reality of centralized evaluation of special requests, we see it as a way to think through the different results this process may have. Specifically, the comparison highlights the possibility that centralizing the evaluation of requests for special consideration may not have the desired consequences. 


\section{Conclusions}

We started this journey with several questions in mind: Why isn't the university providing us with more guidance on these ethical dilemmas? Why isn't there a larger conversation happening around these dilemmas? What are the best practices for responding to requests for special academic consideration? Should these decisions even be made by individual faculty?

The massification of universities has led to a greater involvement of administrators (Macfarlane, 2002; Macfarlane, 2004). However, decisions about exceptions to course policies-requests for academic consideration, requests for special treatment, everyday ethical dilemmas, whatever label you want to give them-still largely belongs in the hands of individual instructors.

Centralizing these requests for special treatment would certainly make things simpler for individual instructors. However, the centralization of academic integrity has not delivered on the promise. Academic integrity is still a problem, but faculty feel less like it is their problem (MacLeod, 2014). Arbitrary decisions have been replaced by overly rigid decisions, and "genuine individual needs and differences can be overlooked in well-meaning attempts to maintain fairness to the majority" (Macfarlane, 2004, p. 17). But fairness and equitability does not mean treating all students the same. Individual circumstances and issues of diversity should matter.

At the same time, taking these decisions out of the hands of instructors further erodes autonomy and academic freedom, and implies an institution's lack of trust in faculty to make these decisions (Macfarlane, 2004). Moreover, allowing instructors to opt out of these decisions moves faculty further away from a reflective practice. The danger is a system that devolves into one in which no one is thinking critically about these issues; everyone is simply following a prescribed set of imperfect rules. As reluctant as we are to admit it, faculty should want to keep the power to make these decisions to ensure that we are self-critical, flexible, reflective, and considerate of the diversity of our students' needs. In examining the centralization of academic integrity, we also want to keep the power to make decisions about requests for special consideration to avoid an overly bureaucratic process that is time-consuming for faculty, but ultimately fails to consider their opinions.

Educators struggle with ethical dilemmas because they have no moral vocabulary with which to understand their moral judgments (ShapiraLischinsky, 2011). There is no best practice for how to respond to these dilemmas. Every instructor needs to consider his or her own ethical ideology, and which contextual variables may or may not play a role in his or her decisions about these dilemmas. However, there is one best practice that we advocate: instructors should take the time to reflect on these decisions and their outcomes. With no clear path to what is morally right, the outcomes of past decisions are the only real insight into how we should be making these decisions. In this way, instructors are able to develop consistency within their own decision-making process, leading to greater transparency to their students. As with so much of pedagogy, careful reflection is the key to improving our practice.

\section{References}

Altbach, P. G., Reisberg, L., \& Rumbley, L. E. (2009). Trends in global higher education: Tracking an academic revolution. United Nations Educational, Scientific and Cultural Organization.

Barnett, R. (2004). Foreword. In Macfarlane, B. (Ed.), Teaching with integrity: The ethics of higher education practice (v-vii). New York, NY: Routledge.

Beran, T., Violato, C., \& Kline, D. (2007). What's the "use" of student ratings of instruction for administrators? One university's experience. Canadian Journal of Higher Education, 37(1), 2743. 
Brown, L. I. (2004). Diversity: The challenge for higher education. Race Ethnicity and Education, 7(1), 21-34.

Devlin, M. (2015). Ombudsperson calls for centralized academic integrity office on campus. The Gazette, 108(94), 3.

Eiszler, C. F. (2002). College students' evaluations of teaching and grade inflation. Research in Higher Education, 43(4), 483-501.

Felder, R. M., \& Brent, R. (2005). Understanding student differences. Journal of Engineering Education, 94(1), 57-72.

Fenwick, T. (2005). Ethical dilemmas of critical management education within classrooms and beyond. Management Learning, 36(1), 31-48.

Forsyth, D. R. (1980). A taxonomy of ethical ideologies. Journal of Personality and Social psychology, 39(1), 175.

Gallant, T. B., \& Drinan, P. (2006) Institutionalizing academic integrity: Administrator perceptions and institutional actions. NASPA Journal 43, 61-81.

Gravestock, P., \& Gregor-Greenleaf, E. (2008). Student course evaluations: Research, models and trends. Toronto: Higher Education Quality Council of Ontario.

Greenwald, A. G., McGhee, D. E., \& Schwartz, J. L. (1998). Measuring individual differences in implicit cognition: The implicit association test. Journal of Personality and Social Psychology, 74(6), 1464-1480.

Hughes, J. M. C., \& McCabe, D. L. (2006) Academic misconduct within higher education in Canada. Canadian Journal of Higher Education 36, $1-21$.
Macfarlane, B. (2004). Teaching with integrity: The ethics of higher education practice. New York, NY: Routledge.

Macfarlane, B. (2002). Dealing with Dave's dilemmas: Exploring the ethics of pedagogic practice. Teaching in Higher Education, 7(2), 167178.

MacLeod, P. D. (2014). An exploration of faculty attitudes toward student academic dishonesty in selected Canadian universities (unpublished doctoral thesis). University of Calgary, Calgary, Alberta.

Meister, J. (2015) Office of the Ombudsperson annual report 2013/14, Western University. London, ON.

Milkman, K. L., Akinola, M., Chugh, D. (2015). What happens before? A field experiment exploring how pay and representation differentially shape bias on the pathway into organizations. Journal of Applied Psychology, 100(6), 1678-1712.

Nasser, F., \& Fresko, B. (2002). Faculty views of student evaluation of college teaching. Assessment \& Evaluation in Higher Education, 27(2), 187198.

Neufeld, J., \& Dianda, J. (2007). Academic dishonesty: A survey of policies and procedures at Ontario Universities. Council of Ontario Universities.

Scott, S. V. (1999). The academic as service provider: is the customer 'always right'?. Journal of Higher Education Policy and Management, 21(2), 193202.

Shapira-Lishchinsky, O. (2011). Teachers' critical incidents: Ethical dilemmas in teaching practice. Teaching and Teacher Education, 27(3), 648-656.

Sleeter, C. E. (2015). Equity and race-visible urban school reform. In M. Khalifa, C. Grant, M. W. 
Arnold, \& A. F. Osanloo (Eds.), Handbook of urban educational leadership (pp. 135-146). Lanham, MD: Rowman \& Littlefield.

\section{Acknowledgements}

We thank the participants of our session at STLHE who engaged with us in this discussion, and helped to shape this essay. We also thank iClicker for providing us with a set of remotes to collect participants' responses while allowing our participants to maintain their privacy in terms of their own ethical values and ideologies.

\section{Biographies}

Kristie Dukewich, $\mathrm{PhD}$ is a faculty member in Psychology at Kwantlen Polytechnic University. Her pedagogical inquiry and research involves best practices for slide design, reflective writing, and ethical dilemmas in teaching.

Suzanne Wood, PhD is an Assistant Professor, Teaching Stream in the Psychology Department at the University of Toronto. Her teaching and research focuses on the intersection of neuroscience and behaviour. 


\title{
Appendix A \\ Vignettes presented in the session
}

\author{
Ethical Ideologies Key²: \\ $A=$ Absolutist $\quad B=$ Exceptionist $\quad C=$ Situationist $\quad D=$ Subjectivist
}

1. "Late Homework"

You are an instructor at a large university. You teach one of the larger second year courses in Chemistry. One of your students has come to office hours to ask for an exception. The student had completed the homework that was due yesterday and claims the homework was actually completed well in advance, but the student forgot to turn it in yesterday between classes because he was preoccupied by a recent breakup. Because the homework assignments are worth so little (only $5 \%$ per assignment), your course policy is that late submissions are not accepted. The student is one that you know very well, and you believe his story about the break-up. The student is asking you to make an exception to this rule and allow him to turn in his assignment without penalty. Which of the following courses of action would you be most likely to take?

A. Tell the student sorry, but that you must be fair and equitable to all students, and it would be unfair to accept the late homework without offering similar accommodation to the whole class.

B. Tell the student that if he can provide documentation that his personal issues have significantly impacted his academic performance, you will accept the late submission this once.

C. You have empathy for the student, and you negotiate to accept the homework with a small late penalty applied. That way he has not escaped without consequence, but the punishment is more fitting.

D. Based on your gut feeling and personal knowledge of the student, you believe the student is actually very contrite and very affected by the breakup, and it feels wrong to penalize him for the situation, so you accept the homework.
3. "Late Penalty"

You are an instructor at a mid-sized university. You teach the introductory $1^{\text {st }}$ year course in Psychology in which students are required to submit two short reflective writing assignments during the course, one in the $1^{\text {st }}$ semester, one in the $2^{\text {nd }}$ semester. All assignments are submitted electronically through the online course management system, which automatically calculates late deductions at $10 \%$ per day or part thereof. One student submitted his assignment 73 seconds late, and has come to your office hours to complain about the late deduction. The student argues that he didn't realize he submitted after the deadline because his computer had a timestamp different from the course management system. Even so, he feels that losing $10 \%$ of the assignment grade for being a minute late is unreasonable. Which of the following courses of action would you be most likely to take?

A. Tell the student sorry, but he was aware of the deadline and didn't give himself enough time to submit and he will have to accept the consequences.

B. You agree with the student $-10 \%$ for a little over a minute late is unfair so you make an exception, but you go back and check all of the submissions to make sure that anyone who submitted up to 2 minutes late isn't penalized either.

C. You consider the fact that the student is $1^{\text {st }}$ year, and that the punishment is disproportionate compared to the crime, but you feel there should be some consequence for the student so you negotiate to only take a 5\% deduction, rather than the full $10 \%$.

D. The student was rude in his approach, did not seem sincere, and making an exception would generate work for you, so you decline to give him a break.

\footnotetext{
${ }^{2}$ While we attempted to align our voting options with Foryth's ethical ideologies, we acknowledge the alignment was not always perfect.
} 


\section{2. "Extension"}

You are an instructor at a small university. You teach a fourth year seminar course in Linguistics with 15 students. One of your students has come to office hours to ask for an exception. The term paper is due today, but the student is asking for a 3-day extension. The student is registered with Accessibility Services, and claims to be having a disability-related flare-up but doesn't have documentation or confirmation from Accessibility Services. He needs the 3 days to put the finishing touches on the term paper. You strongly suspect the student is using his disability as an excuse for not managing his time effectively, but the draft he brought with him is $70 \%$ finished. Which of the following courses of action would you be most likely to take?

A. Tell the student sorry, but that you must be fair and equitable to all students, and it would be unfair to grant an extension without offering similar accommodation to the whole class.

B. Tell the student that if he can provide documentation of his flair-up, you will grant the 3day extension.

C. There is clear evidence that the student has at least started working on the paper in earnest, and it is possible that he is having a flare-up of his disability, so you grant the extension.

D. Considering your strong suspicion that he is using his disability as an excuse, so you tell the student that he can submit late but he will take the same late penalty as any other student in the class.

\section{4. "Grade Bump"}

You are an instructor at a relatively large college in a big city. You teach a variety of English courses. After the grades for your courses have been submitted, you receive a visit from one of your students who timidly knocks at your door and asks if she can please speak with you for a minute. The student has come to ask for a grade bump. She earned a grade of $83 \%$ in your second year English course on Shakespeare but she was hoping to get an $85 \%$, which bump her up to an $\mathrm{A}+$ letter grade. If she were to get an $\mathrm{A}+$ in your course, she would be eligible for a college bursary for academic excellence. She lives at home with her parents, who pay for her school, and she would like to give the bursary to them - a token of her hard work and appreciation. She finishes her speech, she tells you that she understands if you say no, but that it was worth a shot, and she wants to thank you for a great semester. Which of the following courses of action would you be most likely to take?

A. You politely tell the student that while you sympathize with her situation, you can't change a student's grade just because they ask - it's not fair to other students in the course.

B. Tell the student that if she can find reason for you to change her grade after reviewing all of her term work and her final exam, you will consider a grade appeal based on this evidence.

C. Considering the circumstances, you tell her that if she completes a special bonus assignment to your satisfaction, you will award her the A+.

D. The student is so close to an $\mathrm{A}_{+}$, and you recognize that if she'd scored $0.9 \%$ higher, she would have legitimately earned the A+. She was polite and earnest, and helping the student earn a bursary feels like the right thing to do so you give her the grade bump. 


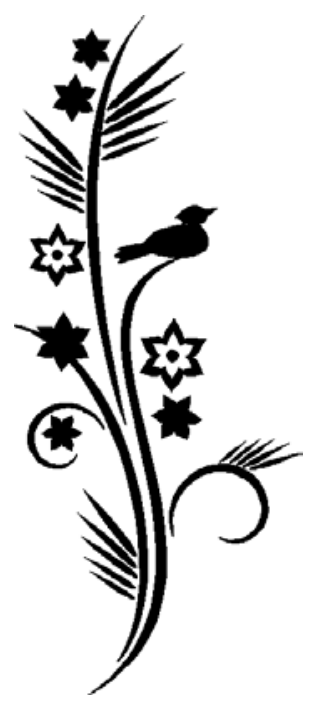

